\title{
Changes in Contents of Free Amino Acids, Trimethylamine, and Nonprotein Nitrogen of Oyster during Ice Storage*1
}

\author{
Michiyo Murata*2 and Morihiko Sakaguchi*2 \\ (Accepted April 25, 1986)
}

\begin{abstract}
The contents of free amino acids (FAA) in the whole body and adductor muscle of oyster Crassostrea gigas, which had been stored in ice until they reached early stage of spoilage, were measured. Trimethylamine (TMA), and nonprotein nitrogen (NP-N) together with volatile base nitrogen (VB-N) and trimethylamine oxide (TMAO), were also determined. The content of VB-N at 0 day was relatively low $(10.5$ and $8.7 \mathrm{mg} / 100 \mathrm{~g})$ and increased significantly thereafter in both the whole body and adductor muscle during storage for 2 weeks. Only a little TMAO was detected and TMA was about $5 \mathrm{mg} / 100 \mathrm{~g}$; there was almost no change in the contents during storage in either the whole body or adductor muscle. NP-N was $485 \mathrm{mg} / 100 \mathrm{~g}$ in the whole body and $515 \mathrm{mg} / 100 \mathrm{~g}$ in the adductor muscle at 0 day, and no measurable change thereafter. In fresh whole body, the level of taurine was extremely high $(974 \mathrm{mg} / 100 \mathrm{mg})$ and the amounts of glycine, proline, glutamic acid, and alanine were relatively large. Taurine and glycine changed little throughout the storage period. Alanine showed a slight increase, while proline and glutamic acid decreased. In fresh adductor muscle, the level of taurine was also high $(768 \mathrm{mg} / 100 \mathrm{~g})$ and the levels of glycine, $\beta$-alanine, arginine, alanine, and proline were relatively high. Taurine and glycine exhibited little change during storage. Remarkable increase in alanine and decrease in glutamic acid levels were observed.
\end{abstract}

Flesh of marine bivalves has high levels of nonprotein nitrogenous compounds, whose major components are free amino acids (FAA), betaines, trimethylamine oxide, adenine nucleotides, and related compounds. ${ }^{1)}$. Among them, FAA are markedly abundant and play an important role as intracellular osmolytes. Also, FAA are known to give meaty flavors to fish and shellfish muscle. ${ }^{2)}$ Abalone Nordotis dudcus muscle contains high levels of arginine and glycine. Short-necked clam Tapes japonica muscle has large amounts of glycine, glutamic acid and alanine. ${ }^{1)}$ Scallops Patinopecten yeroensis are rich in arginine and glycine ${ }^{3,4)}$ and oyster Crassostrea gigas and Crassostrea virginica in alanine and glycine. ${ }^{3,5-7)}$ In addition to these molecular species of FAA, taurine is amply found in most molluscan muscle. ${ }^{17}$ Recently, this substance has been recognized as nutritionally important for humans and other mammals. ${ }^{8, \theta)}$

In oyster, in spite of its commercial importance, the changes in FAA and taurine levels during storage have not been investigated sufficiently. The major objective of this study was to examine these changes during ice storage of oyster meat ranging from fresh to aged through early stage of spoilage. The changes in contents of trimethylamine (TMA), trimethylamine oxide (TMAO), nonprotein nitrogen $(\mathrm{NP}-\mathrm{N})$, and volatile base nitrogen (VB-N) were also examined.

\section{Materials and Methods}

Sixty oysters, weighing approximately $400 \mathrm{~g}$, were purchased from a local market in November 1984. They were shucked carefully to prevent contamination by small pieces of broken shell. Whole body thus obtained was lightly rinsed with ice-cold $1.5 \%$ sodium chloride solution and drained briefly. Adductor muscle was removed from the whole body. The whole body weighing 7.9 to $15.6 \mathrm{~g}$ and the adductor muscle of 0.6 to $1.9 \mathrm{~g}$ were put in separate glass containers and left for approximately $1 \mathrm{~h}$ in ice to exude excess body fluid. For sampling, groups of 5 whole bodies and 6 adductor muscles were sealed in separate polyethylene containers and placed in ice during storage. Subsequently, the whole bodies (10.8-

*1 A part of the study was presented at the annual meeting of the Japanese Society of Scientific Fisheries, Tokyo, April 1985.

*2 The Research Institute for Food Science, Kyoto University, Uji, Kyoto 611, Japan（村田道代, 圾口守楌: 京都大学食数科学研究所). 


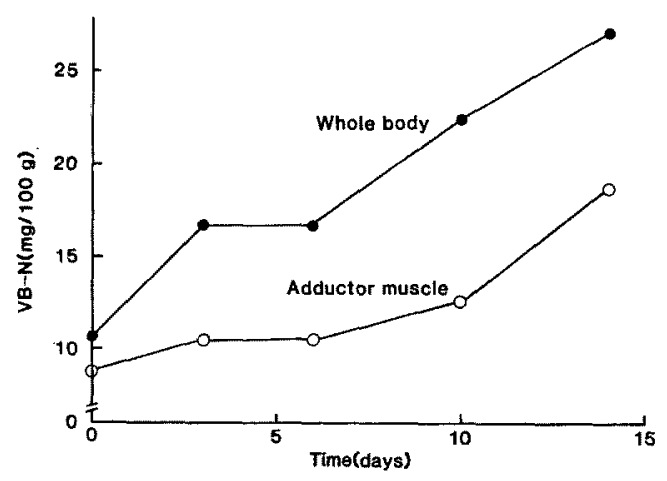

Fig. 1. VB-N levels in the whole body and the adductor muscle stored for various periods in ice.

$12.7 \mathrm{~g}$ each) and a $5.0 \mathrm{~g}$ portion from the adductor muscles were submitted to extraction and determination of FAA, VB-N, TMAO, and NP-N. The method for extraction with trichloroacetic acid (TCA) was the same as described previously. ${ }^{103}$ The TCA extract was washed 4 times with a similar volume of diethylether and the $\mathrm{pH}$ was adjusted to about 2.2. An aliquot of the extract was submitted to an analysis of FAA and taurine on an amino acid analyzer (Hitachi model 835).

VB-N and NP-N were estimated in the same manner as described previously. ${ }^{10)}$ TMA and TMAO were measured by the methods of Tozawa et al. ${ }^{11}$ and Bystedt et al., ${ }^{12)}$ respectively.

\section{Results}

\section{$V B-N$}

Fig. 1 shows changes in the levels of VB-N in the whole body and adductor muscle during ice storage. Before storage, the amount of VB-N in both was approximately $10 \mathrm{mg} / 100 \mathrm{~g}$; the value for the whole body was slightly higher than that for the adductor muscle. In the whole body, there was a relatively rapid increase within the initial 3 days, which was then followed by a 2nd increase after about 6 days. The adductor muscle exhibited a slow increase within the initial several days and a rapid increase thereafter.

\section{TMA and TMAO}

Fig. 2 shows changes in the quantities of TMA and TMAO in the whole body and adductor muscle during ice storage. At 0 day, TMA quantities were approximately $5 \mathrm{mg} / 100 \mathrm{~g}$ and $4 \mathrm{mg} / 100 \mathrm{~g}$ for the whole body and adductor

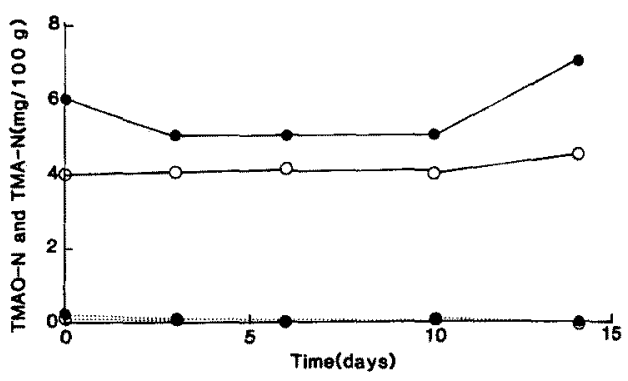

Fig. 2. TMAO and TMA contents in the whole body and the adductor muscle stored for various periods in ice. TMAO in the whole body; $O-O$, TMAO in the adductor muscle; - - TMA in the whole body, $0-0$, TMA in the adductor muscle.

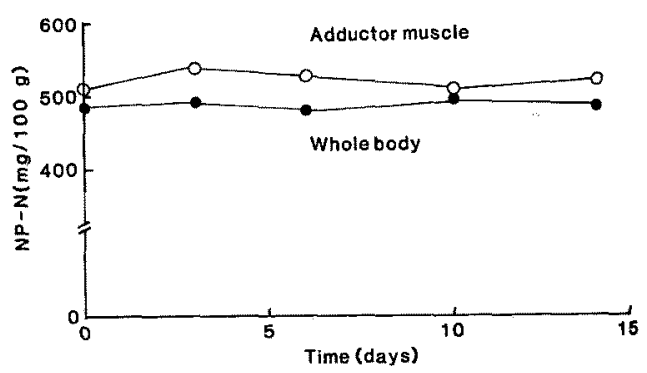

Fig. 3. NP-N levels in the whole body and the adductor muscle stored for various periods in ice.

muscle, respectively. There was no measurable change during the entire storage period. Little TMAO was detected in the fresh whole body and adductor, being a result similar to that reported so far for oyster. ${ }^{13-15)}$ Also, there was little change in the levels of TMAO in both the whole body and adductor muscle during strorage.

$N P-N$

Fig. 3 shows changes in the levels of NP-N in the whole body and adductor muscle during 2 weeks of storage. Initially, whole body had 491 $\mathrm{mg} / 100 \mathrm{~g}$ of NP-N while the adductor muscle had more than this. Both levels remained almost unchanged throughout the storage period. This NP-N value for the fresh whole body is lower than that for short-necked clam but is a little higher than the values for oyster as reported by Takagi and Simidu. ${ }^{13)}$ 
Table 1. Contents of free amino acids (FAA) in the fresh whole body and adductor muscle of oyster (mg/100 g)

\begin{tabular}{lcc}
\hline FAA & Whole body & $\begin{array}{c}\text { Adductor } \\
\text { muscle }\end{array}$ \\
\hline Taurine & 974 & 768 \\
Aspartic acid & 49.4 & 22.7 \\
Threonine & 61.7 & 36.1 \\
Serine & 27.6 & 9.5 \\
Glutamic acid & 124 & 92.7 \\
Proline & 138 & 99.7 \\
Glycine & 210 & 529 \\
Alanine & 123 & 98.0 \\
Valine & 10.3 & 7.3 \\
Cystine & 6.7 & 3.9 \\
Methionine & 10.0 & 1.8 \\
Isoleucine & 5.8 & 2.4 \\
Leucine & 14.2 & 6.3 \\
Tyrosine & 11.7 & 4.0 \\
Phenylalanine & 5.1 & 5.6 \\
B-Alanine & 46.5 & 142 \\
Lysine & 14.8 & 5.9 \\
Histidine & 33.4 & 25.2 \\
Arginine & 54.5 & 106 \\
\hline
\end{tabular}
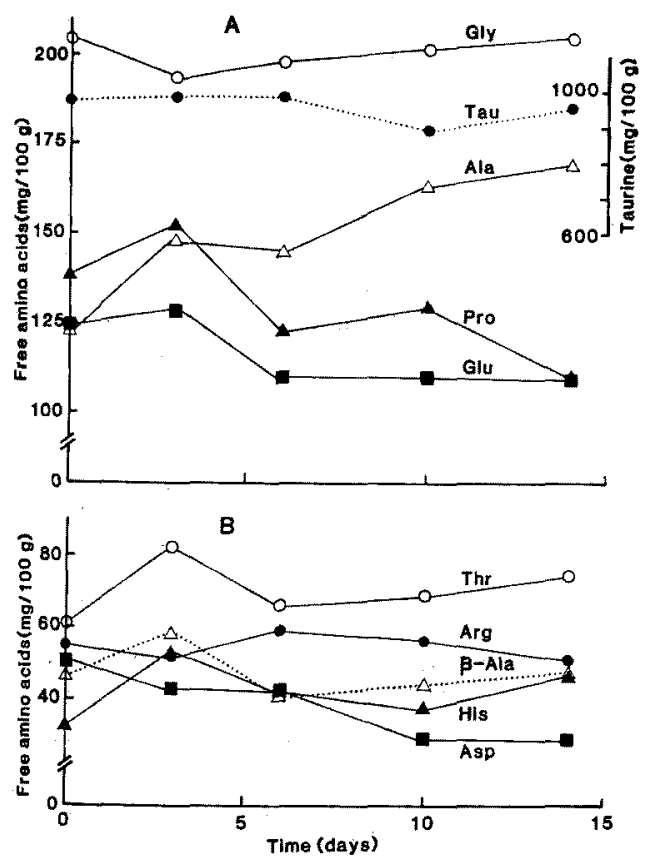

Fig. 4. Changes in FAA contents in the whole body during storage in ice.

A: $\triangle-\triangle$, Alanine; $\mathbf{n - n}$, Glutamic acid; $\bigcirc-\mathrm{O}$, Glycine; $\triangle-\wedge$, Proline; $--\boldsymbol{-}$, Taurine. B: $\mathbf{\square -}$, Aspartic acid; $\triangle--\Delta, \beta$-Alanine; $-\infty$, Arginine; $\Delta-\Delta$, Histidine; $\mathrm{O}-\mathrm{O}$, Threonine.

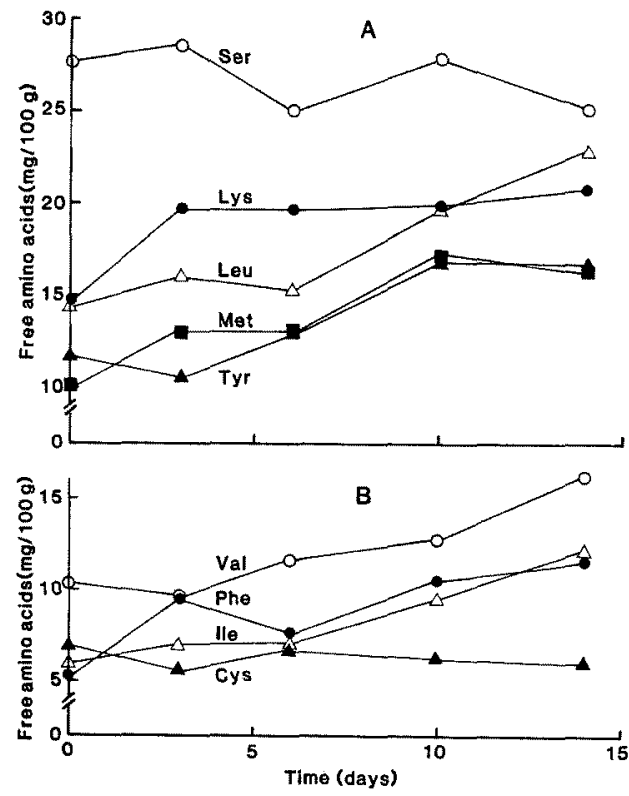

Fig. 5. Changes in FAA contents in the whole body during storage in ice.

A: $\triangle-\triangle$, Leucine; $\bullet-\bullet$, Lysine; $\mathbf{\square}-\mathbf{\square}$, Methionine; $O-O$, Serine; $\Delta-\Lambda$, Tyrosine. B: $\Delta-\Delta$, Cystine; $\Delta-\Delta$, Isoleucine; $-\bullet$, Phenylalanine; $\mathrm{O}-\mathrm{O}$, Valine.

\section{Free Amino Acids in Fresh Meat}

The contents of free amino acids (FAA) in the fresh whole body and adductor muscle are given in Table 1. Compared with other FAA in the whole body, the quantity of taurine was extremely high, while glycine, proline, glutamic acid, and alanine were also present at fairly high levels. Appreciable amounts of threonine, arginine, aspartic acid, $\beta$-alanine, and histidine were found. All others were smaller than $30 \mathrm{mg} / 100 \mathrm{~g}$ in concentration. The adductor muscle had an extremely high level of taurine and a markedly large amount of glycine. Relatively high levels of $\beta$ alanine, arginine, proline, and alanine were found, while threonine, histidine, and aspartic acid were present in a range of $10-40 \mathrm{mg} / 100 \mathrm{~g}$. Concentrations of all others were smaller than this. Of the FAA occurring in large amounts, more glycine, $\beta$-alanine, and arginine were found in the adductor muscle than in the whole body. So far there have been many reports on oyster FAA levels but only a few have reported the existence of such a high content of $\beta$-alanine. 


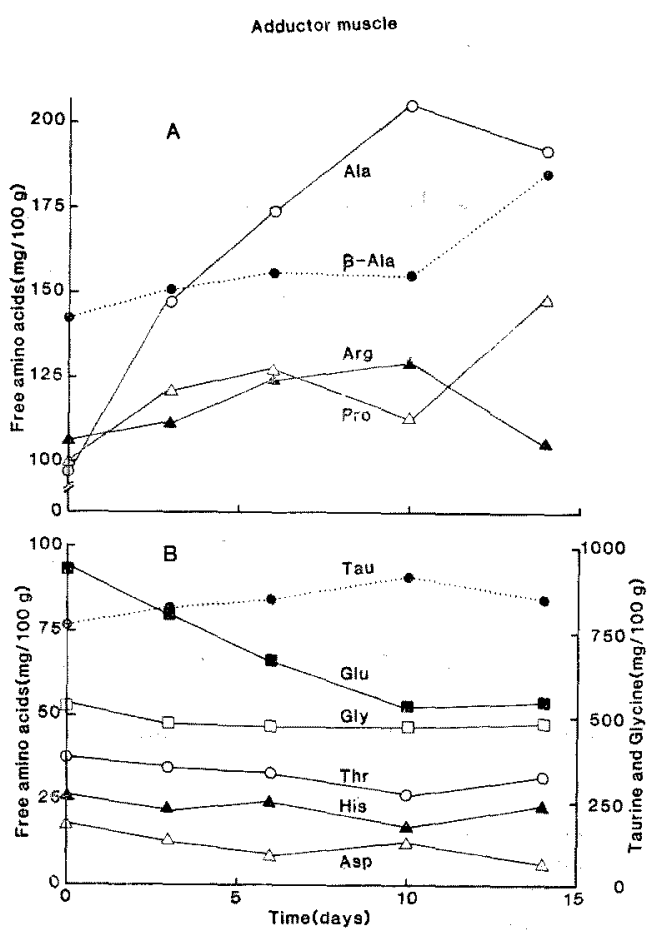

Fig. 6. Changes in FAA contents in the adductor muscle during storage in ice.

A: $\bigcirc-O$, Alanine; $\bullet--\bullet, \beta$-Alanine; $\Delta-\Lambda$, Arginine; $\triangle-\Delta$, Proline, $B: \triangle-\Delta$, Aspartic acid; $\mathbf{D}$, Glutamic acid; $\square-\square$, Glycine; A-A, Histidine; ---o, Taurine, $\mathrm{O}-\mathrm{O}$, Threonine.

\section{Changes in Amounts of FAA during Ice Storage}

Fig. 4 and 5 and Fig. 6 and 7 depict changes in FAA levels during ice storage of the whole body and adductor muscle, respectively. In the whole body, there was a marked increase in alanine (Fig. 4-A). Proline increased slightly within the initial 3 days and decreased thereafter. Glutamic acid also decreased slightly after the initial 3 days of storage. Taurine and glycine, both of which were extremely high in levels, did not show any distinct changes (Fig. 4-A). Aspartic acid decreased a little (Fig. 4-B). Threonine, arginine, $\beta$-alanine, and histidine increased initially but thereafter their levels remained mostly unchanged. The others, except for serine and cystine which showed no measurable change during storage, exhibited an increasing trend more or less (Fig. 5-A and 5-B).

In the adductor muscle, alanine increased greatly in level from $98 \mathrm{mg} / 100 \mathrm{~g}$ initially (Table 1) to $206 \mathrm{mg} / 100 \mathrm{~g}$ on the 10 th day (Fig. 6-A). Glutamic acid, in contrast, kept decreasing through
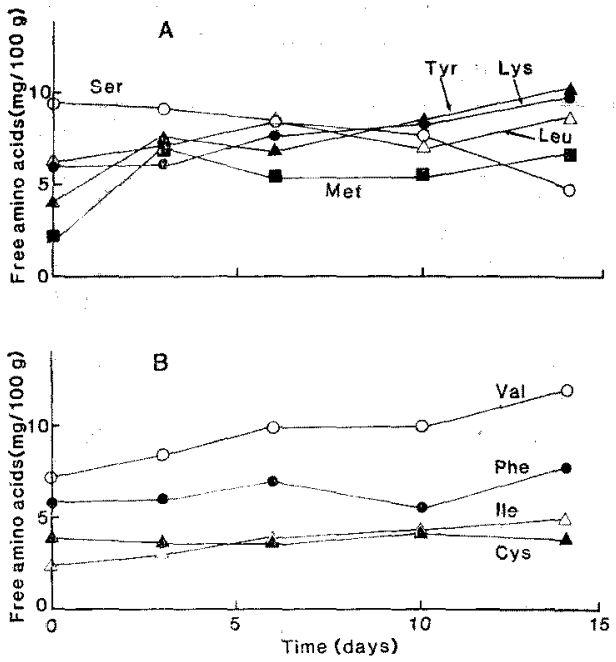

Fig. 7. Changes in FAA contents in the adductor muscle during storage in ice.

Symbols in A and B are the same as those given in the footnote of Fig. 5.

initial 10 days of storage (Fig. 6-B), $\beta$-Alanine showed little change in concentration during the initial 10 days, then increased sharply after that. Arginine and proline levels fluctuated. This pattern of changes in level of these compounds was different from that of the whole body which showed a decreasing tendency. Taurine and glycine changed little during storage; threonine, histidine, and aspartic acid remained almost unchanged. The others that were less than $10 \mathrm{mg} /$ $100 \mathrm{~g}$ showed also no measurable changes (Fig. 7-A and 7-B).

\section{Discussion}

In the whole body after 6 days of storage the VB-N level reached about $17 \mathrm{mg} / 100 \mathrm{~g}$ (Fig. 1). The meat seemed to be at the onset of bacterial spoilage, because the samples had lost the smell specific to fresh oyster meat and had a considerably unacceptable smell. All samples stored for longer periods had also an unacceptable smell. Takagi and Simidu, ${ }^{10)}$ who observed changes in the taste of samples stored at $-2^{\circ}-3^{\circ} \mathrm{C}$, found that the sample stored for 8 days was unacceptable. In the adductor muscle, the VB-N level was at 18.8 $\mathrm{mg} / 100 \mathrm{~g}$ after 6 days (Fig. 1). The muscle, however, could not be thought to be spoiled, because the sample was still acceptable so long as odor. 
Among FAA present in both the fresh whole body and adductor muscle, taurine was found in extremely large quantities (Table 1). Generally, the level of taurine is high in many tissues of marine bivalves, ${ }^{17,}{ }^{18)}$ because taurine functions as an osmotic constituent. There was little change in the taurine level during the entire storage period (Fig. 4-A and 6-B), suggesting that the compound is highly stable. This characteristic has also been reported for cod as well as yellowtail muscle stored in ice. ${ }^{10,19)}$ Therefore, the role of taurine in mammalian nutrition would not be affected by low temperature storage of fish and shell fish. In addition to taurine, it has been reported that fresh muscle of oyster contains large amounts of alanine, glutamic acid, glycine, and proline. ${ }^{5-7)}$ This is common to all marine bivalves. ${ }^{1,2}$ Q Quantities of taurine and individual FAA in bivalve muscle, of course, differ considerably from species to species. ${ }^{1)}$ The quantities even in the same species vary with the diet, season, temperature, and environmental stresses such as anaerobiosis and osmotic pressure. ${ }^{20)}$ During storage, some amounts of alanine and glycine appear to have been metabolized to alanopine and strombine, respectively. In live oysters, these opines are produced more or less in the adductor muscle. $^{21-24)} \mathrm{A}$ high level of $\beta$-alanine was detected in the adductor muscle (Fig. 6-A). In the muscle tissue of bivalves such as Ostrea gigas, ${ }^{25)}$ Saccostrea commercialis, Anadara trapezia, ${ }^{28)}$ and $A$. broughtoni $i,{ }^{27)} \beta$-alanine exists in significantly large amounts. This substance is also found in the gill tissue of oyster C. virginica ${ }^{28)}$ where it functions as an osmotic effector. Another of the FAA found in large amounts in the adductor muscle was arginine (Fig. 6-A). This amino acid might have been derived from argininephosphate during storage. The latter compound, which is present in a high concentration in the live muscle, plays an important part as phosphagen, which produces energy upon shell closure. Generally, bivalves contain a large amounts of glycogen which serves as energy reservor to enable them to endure anoxia for long periods. ${ }^{20)}$ Alanine, a constituent of osmolytes, is a major end product of the carbohydrate fermentation upon anaerobic respiration. During this process, alanine is derived from pyruvate by transamination of glutamic acid. In fact, ${ }^{14} \mathrm{C}$-pyruvate is incorporated into alanine in the adductor muscle of scallop Placopecten magellanicus during ice storage. ${ }^{20)}$ This is possibly the reason why alanine showed an increase and glutamic acid a decrease in level in the post mortem oyster tissue. In the later periods of storage of the adductor muscle, there was a markedly high increase in $\beta$-alanine and proline and decrease in alanine and arginine. Although the reason is unclear, it is likely that bacterial action, to some extent, was responsible, because VB-N began to increase sharply in these periods (Fig. 1). Increases in isoleucine, leucine, lysine, methionine, phenylalanine, threonine, tyrosine, and valine were found in the whole body and increases in lysine, methionine, tyrosine, and valine were found in the adductor muscle (Fig. 5 and 7). Since NP-N levels exhibited little change throughout the storage period (Fig. 2), the possibility that these FAA came from protein breakdown can be ruled out.

Among FAA, glutamic acid, alanine, arginine, and glycine are major taste-producing factors, as recognized in abalone, crab, and dried bonito extracts. ${ }^{2,31)}$ The latter 3 amino acids did not decrease in level until the initial 6 days of ice storage of the oyster whole body and even glutamic acid levels remained largely (Fig. 4). On the 6th day, however, the whole body a substantially edible portion of oyster was unacceptable due to unpleasant odor.

\section{References}

1) S. Konosu and K. Yamaguchi: "Chemistry and Biochemistry of Marine Food Products", (ed. by R. E. Martin, G. J. Flick, C. E. Hebard, and D. R. Ward), AVI Publishing Co., Connecticut, 1982, pp. 367-404.

2) Y. Hashimoto: "The Technology of Fish Utilization" (ed. by R. Kreuzer), Fishing News Books, London, 1965, pp. 57-61.

3) M. Takagi, A. Iida, H. Murayama, and S. Soma: Bull. Fac. Fish. Hokkaido Univ., 21, 128-132 (1970).

4) K. Oishi, A. Iida, and A. Yoshimura: Bull. Japan. Soc. Sci. Fish., 36, 1226-1230 (1970).

5) M. L. Lynch and L. Wood: Comp. Biochem. Physiol., 19, 783-790 (1966).

6) S. E. Shumway, P. A. Gabbot, and A. Youngson: J. Exp. Mar. Biol. Ecol., 29, 131-150 (1977).

7) B.W. Heavers and C.S. Hammen: Comp. Biochem. Physiol., 82A, 571-576 (1985).

8) J. A. Sturman: Prog. Clin. Biol. Res., 125, 281295 (1983).

9) G. E. Gaull, H. P. Morales, and C. E. Wright: Prog. Clin. Biol. Res., 179, 3-21 (1985).

10) M. Sakaguchi, M. Murata, and A. Kawai: $J$. Food Sci., 47, 1662-1666 (1982).

11) H. Tozawa, K. Enokibara, and K. Amano: Bull. Japan. Soc. Sci. Fish., 36, 606-611 (1970).

12) J. Bystedt, L. Swenne, and W. A. Aas: J. Sci. 
Food Agric., 10, 301-304 (1959).

13) I. Takagi and W. Simidu: Bull, Japan. Soc. Sci. Fish., 28, 1192-1198 (1962).

14) W. Dyer: J. Fish. Res. Bd. Can., 8, 314-324 (1952).

15) K. Harada, J. Takeda, and K. Yamada: Suisan Daigaku-ko Kenkyu Hokoku., 18, 11-19 (1970).

16) I. Takagi and W. Simidu: Bull. Japan. Soc. Sci. Fish., 29, 71-74 (1963).

17) J. A. Allen and M. R. Garrett: Adv. Mar, Biol., 9, 205-253 (1971).

18) A. Ozawa, S. Aoki, K. Suzuki, M. Sugimoto, T. Fujita, and K. Tsuji: J. Japan. Soc. Nutr. Food Sci., 37, 561-567 (1984).

19) J. M. Shewan and N. R. Jones: J. Sci. Food Agric, 8, 491-498 (1957).

20) S. H. Bishop, L. L. Ellis, and J. M. Burcham: "The Mollusca" (ed. by P. W. Hochachka), vol. 1, Academic Press Inc., New York, 1983, pp. 243327.

21) J. H. Fields, A. K. Eng, W. D. Ramsden, P. W. Hochachka, and B. Weinstein: Arch. Biochem. Biophys., 201, 110-114 (1980).
22) M. Sato, Y. Sato, and Y. Tsuchiya: Bull. Japan. Soc. Sci. Fish., 48, 1411-1414 (1982).

23) B. Siegmund and M. K. Grieshaber: HoppeSeyler's Z. Physiol. Chem., 364, 807-812 (1983).

24) J. C. Eberlee, J. M. Storey, and K. B. Storey: Can. J. Zool., 61, 2682-2687 (1983).

25) S. E. Severin, A. A. Boldyrev, and A. V. Lebedev: Comp. Biochem. Physiol., 43B, 369-381 (1972).

26) A. M. Ivanovici, S. F. Rainer, and V. A. Wadley: Comp. Biochem. Physiol., 70A, 17-22 (1981).

27) D. J. Song, S. Konagaya, K. Nakamura, H. Jida, and T. Tanaka: Trans. $J A R, 1,39-43$ (1984).

28) E. N. Powell, M. Kasschau, E. Chen, M. Koenig, and J. Pecon: Comp. Biochem. Physiol., 71A, 591-598 (1982).

29) A. de Zwaan: "The Mollusca" (ed. by P.W. Hochachka), vol. 1, Academic Press Inc., New York, 1983, pp. 137-175.

30) M. Sakaguchi, D. F. Hiltz, and W. J. Dyer: J. Fish. Res. Bd. Can., 32, 1329-1337 (1975).

31) T. Hayashi, K. Yamaguchi, and S. Konosu: $J$. Food Sci., 46, 479-483 (1981). 